\title{
Car use reduction: a matter of reasoned calculus, morality or habit? An integrative perspective
}

\author{
Alin Semenescu $^{l *} \&$ Alin Gavreliuc ${ }^{l}$ \\ ${ }^{I}$ Department of Psychology, West University of Timișoara, Romania.
}

Received 29.11.2019; Received revised 27.12.2019; Accepted 28.12.2019

Available online 31.12.2019

\begin{abstract}
Car transportation has many benefits, yet it also generates problems such as noise and air pollution, loss of urban space, traffic jams and contributes significantly to global warming. Three approaches for explaining car use behavior and intentions to reduce it are often used in the transportation literature, namely a rational choice (e.g. theory of planned behavior), a morality-based (e.g. norm activation model) and a habit-based approach. While there were studies that investigated their comparative power, there were relatively few attempts to integrate these different perspectives in a single theoretical model. The present study proposes an integrated model of the theory of planned behavior, the norm activation model and the concept of habits to predict drivers' intentions to reduce their car use, and tests this model on a sample of Romanian drivers $(\mathrm{N}=140)$. Results show that the model performed better than the theory of planned behavior, the norm activation model or a combination of the two and that all variables in the model predicted (directly or indirectly) behavioral intentions to reduce car transportation. The strongest predictors were perceived behavioral control, personal norms and car use related habits. The results contribute to theory development and provide a conceptual framework, which can inform the development of future travel demand management solutions.
\end{abstract}

Keywords: car use, sustainable transportation, theory of planned behavior, norm activation model, habits.

Address of correspondence: Alin Semenescu, Department of Psychology, West University of Timișoara, 4 Vasile Pârvan Blvd., Room 303, 300223 Timișoara, Romania. E-mail: alin.semenescu@e-uvt.ro

\section{Introduction}

Road transportation serves many societal needs, yet it is also responsible for various problems, such as increased levels of noise and air pollution, loss of urban space, traffic congestion or increased mortality rates due to accidents and physical inactivity. It is also responsible for about $20 \%$ of all the carbon dioxide $\left(\mathrm{CO}_{2}\right)$ emitted annually into the atmosphere (Bamberg \& Rees, 2017), thereby contributing significantly to global warming. Technological innovations such as energy-efficient engines, hybrid or electric cars, can potentially reduce its impact on the environment, yet the positive effect of such technologies is counterbalanced by an increase in car ownership and increased frequency of car use. Moreover, even though hybrid and electric vehicles penetrate the market at an increasing rate, conventional engines heavily exceed hybrid and electric ones in sales. For example, the market share of electric vehicles in EU in 2017 was only $1.48 \%$, with only a small increase compared to 2016 (European Environment
Agency, 2018). Therefore, in order to mitigate transportation's impact on global warming, effective travel demand management (TDM) initiatives are still needed.

To devise such policies however, it is essential that the factors that affect car transportation and intentions to reduce it are known and considered by policymakers. The development of models for explaining intention to reduce car transportation is important for understanding the complexities of such decisions, which will then inform future interventions. In the literature, three approaches for explaining intentions to reduce car transportation are often used. The first is a rational choice approach (e.g. theory of planned behavior; Ajzen, 1991), which regards behavior and intentions to reduce it as a result of individual costbenefit calculus. The second is a morality-based approach (e.g. norm activation model; Schwartz, 1977), which assumes that, because pro-environmental behaviors are often costly to the individual, moral considerations are the main determinants of such behaviors. The third is a habitbased approach (e.g. the habit discontinuity hypothesis; 
Bamberg, 2006), which regards car use mainly as an automatic behavior.

The theory of planned behavior (TPB; Ajzen, 1991). TPB stipulates that decisions about behavioral alternatives are influenced by three types of beliefs, namely behavioral beliefs (beliefs derived from judging the likely consequences of available alternatives), normative beliefs (beliefs about the expectations of subjectively important individuals or groups) and control beliefs (beliefs about the availability of resources and about potential obstacles for performing certain behaviors). Such beliefs result, respectively, in the formation of attitudes towards the behavior, subjective norms and perceived behavioral control, which are all assumed to predict behavior through intention formation. Attitudes are conceptualized as the degree of subjectively favorable or unfavorable rational evaluations of the behavior, subjective norms refer to the perceived social pressures from important others to perform or not perform the behavior, while perceived behavioral control is the perceived easiness or difficulty for executing the behavior. TPB has been widely used to predict a multitude of behaviors. In the field of environmental psychology, it was shown to be useful in predicting recycling behavior (e.g. Boldero, 1995), water conservation (e.g. Lam, 1999) or travel mode choice (e.g. Bamberg, Ajzen, \& Schmidt, 2003; Bamberg \& Schmidt, 1998; Bamberg \& Schmidt, 2003; Heath \& Gifford, 2002; Lois, Moriano, \& Rondinella, 2015; Noblet, Thøgersen, \& Teisl, 2014). A recent meta-analysis found general support for TPB concerning car use, by showing that all variables of the model significantly correlated with intentions to use car transportation (Lanzini \& Khan, 2017).

The norm activation model (NAM; Schwartz, 1977). NAM was developed to explain prosocial or altruistic behaviors and assumes that people act pro-environmentally because of moral obligations. According to the model, prosocial behaviors are directly predicted by personal norms, which are conceptualized as feelings of moral obligation that people hold for themselves. Schwartz contended that behavior is influenced by one's personal norms only if the person is aware of the consequences of her/his behavior (awareness of consequences; $A C$ ) and feels responsibility for these consequences (ascription of responsibility; $A R$ ). With respect to car use, the more one realizes the negative consequences of one's behavior for the environment and feels responsible for such consequences, the stronger her/his personal norms to reduce car use will be activated. Personal norms will, in turn, influence intentions to reduce car transportation. In the field of environmental psychology, the NAM was used to predict behaviors such as energy conservation (Black, Stern, \& Elworth, 1985), recycling (Bratt, 1999; Hopper \& Nielsen, 1991), general pro-environmental behavior (Nordlund \& Garvill, 2002) or travel mode choice (e.g. Bamberg \& Schmidt, 2003; Nordlund \& Garvill, 2003). For instance, Nordlund and Garvill (2003) showed that personal norms were direct predictors of willingness to reduce car use in a social dilemma situation.

Even though TPB and NAM are the most used psychological theories in transportation literature (see Chng, Abraham, White, Hoffmann, \& Skippon, 2018), they both neglect the habitual nature of certain behaviors. Since mobility decisions are repeatedly taken under stable context situations, habits can assume an important role in explaining such decisions (Verplanken, Aarts, van Knippenberg, \& van Knippenberg, 1994). Habits are defined as automatic responses triggered by certain events or environmental cues ( Verplanken, Aarts, van Knippenberg, 1997). Strong habits for a particular transportation mode are therefore characterized by less deliberative decisions about transportation alternatives and less information seeking than when habits are weak (Verplanken et al., 1997). In the field of transportation research, studies have shown that habits can be a strong proximal predictor of car use behavior (e.g. Bamberg \& Schmidt, 2003; Eriksson, Garvill, \& Nordlund, 2008) and that they can significantly explain travel mode choice over and above the explanatory power of rational decision processes (e.g. Verplanken, Aarts, van Knippenberg, \& Moonen, 1998; Verplanken et al., 1994).

Considering these three psychological perspectives, an important question arises: Are intentions to use car transportation mainly determined by moral considerations (as the NAM suggests), guided by a rational cost-benefit calculus (as the TPB suggests) or impacted by personal habits? While there were studies investigating the comparative power of TPB, NAM or habits in predicting car use intentions and behavior (e.g. Abrahamse, Steg, Gifford, \& Vlek, 2009; Bamberg et al., 2003; Bamberg \& Schmidt, 2003; Cordano, Welcomer, Scherer, Pradenas, \& Parada, 2011), there were relatively few attempts to integrate these different perspectives in a single model. Understanding intentions to reduce car use from a single theoretical perspective is simplistic and can be misleading, as such decisions are likely a mixture between more influences. Therefore, a much more fruitful endeavor is to investigate how these rational, moral and habitual factors complement each other in explaining intentions to reduce car transport. For example, Liu, Sheng, Mundorf, Redding and Ye (2017) integrated TPB and NAM and showed that personal norms, along with the variables of TPB, significantly predicted intentions to reduce car use in a Chinese sample. Similarly, on a sample of German students, Klöckner and Matthies (2009) used several constructs from TPB and NAM, as well as the construct of habits to predict car use behavior. Their results suggested that habits and perceived behavioral control significantly predicted car use, while the impact of personal norms was non-significant. The most complex model was proposed by Klöckner and Blöbaum (2010), who integrated the TPB, the NAM, the ipsative theory of behavior and the concept of habits in a single model to explain travel mode choice and showed that the integrated model was superior to the TPB or the NAM in explaining car choice behavior.

\section{Present study}

The current study builds upon these endeavors and proposes a model that incorporates only psychological factors, such as moral, rational and habitual influences on intentions to reduce car use. The goal of the present study is to empirically test the validity of the model on a Romanian sample of drivers and to compare its predictive power against the TPB, the NAM and a combination of both. Specifically, the present study will integrate the construct of habits with TPB and NAM constructs to explain driver's intentions to reduce car transportation.

According to TPB, attitudes, subjective norms (SN) and perceived behavioral control (PBC) are direct predictors of intentions. We thus expect that in the integrated model, SN related to car use and $\mathrm{PBC}$ to reduce car transport will positively predict intentions to reduce car use, while attitudes towards car use will negatively predict intentions. 
According to the NAM, intentions are directly predicted by personal norms (PN) which, in turn, are activated when one is aware of the negative environmental consequences (AC) and believes that her/his behavior may alleviate such negative consequences (AR). We thus expect that, in the integrated model, PN about car transport will mediate the relation between $\mathrm{AC}$ and $\mathrm{AR}$, on the one hand, and intentions to reduce car use, on the other hand. Other researchers argue that socialization processes are also responsible for shaping individual moral standards, in such a manner that personal norms originate from internalized social norms (e.g. Klöckner \& Matthies, 2009; Liu et al., 2017). These authors argue that the moral expectations one has over her/his behavior are in fact social expectations from important referees that have been internalized over the course of time. Indeed, research provides empirical support for the link between subjective and personal norms (e.g. Harland, Staats, \& Wilke, 1999; Hunecke, Blöbaum, Matthies, \& Höger, 2001; Liu et al., 2017). We thus expect that $\mathrm{SN}$ related to car use will predict $\mathrm{PN}$ and that PN will mediate the relation between $\mathrm{SN}$ and intentions to reduce car use. Additionally, studies show that children's attitudes towards different transportation modes are shaped through socialization processes (Baslington, 2008; Haustein \& Hunecke, 2007). For example, Baslington (2008) showed that children raised in families that did not own a car claim to need a car significantly less than children raised in families with one or more cars. Because of consistency pressures, the favorable or unfavorable attitudes over car transportation one adopts are likely to influence the type of personal norms one formulates for herself/himself over time. We thus propose that attitudes towards car transportation take precedence over PN about car transportation and will be a significant predictor of the latter. As PN are also a direct predictor of intentions, we also expect that PN will mediate the relation between attitudes towards car transportation and intentions to reduce car use.

As previously argued, besides rational and moral influences, habitual factors also play an important role in transport mode choice. We thus hypothesize that car transport habits will negatively predict intentions to reduce car transportation. In other words, the stronger one's habits are, the weaker the intention to change will be (see Figure 1 for a visual representation of all expected relations in the proposed model).

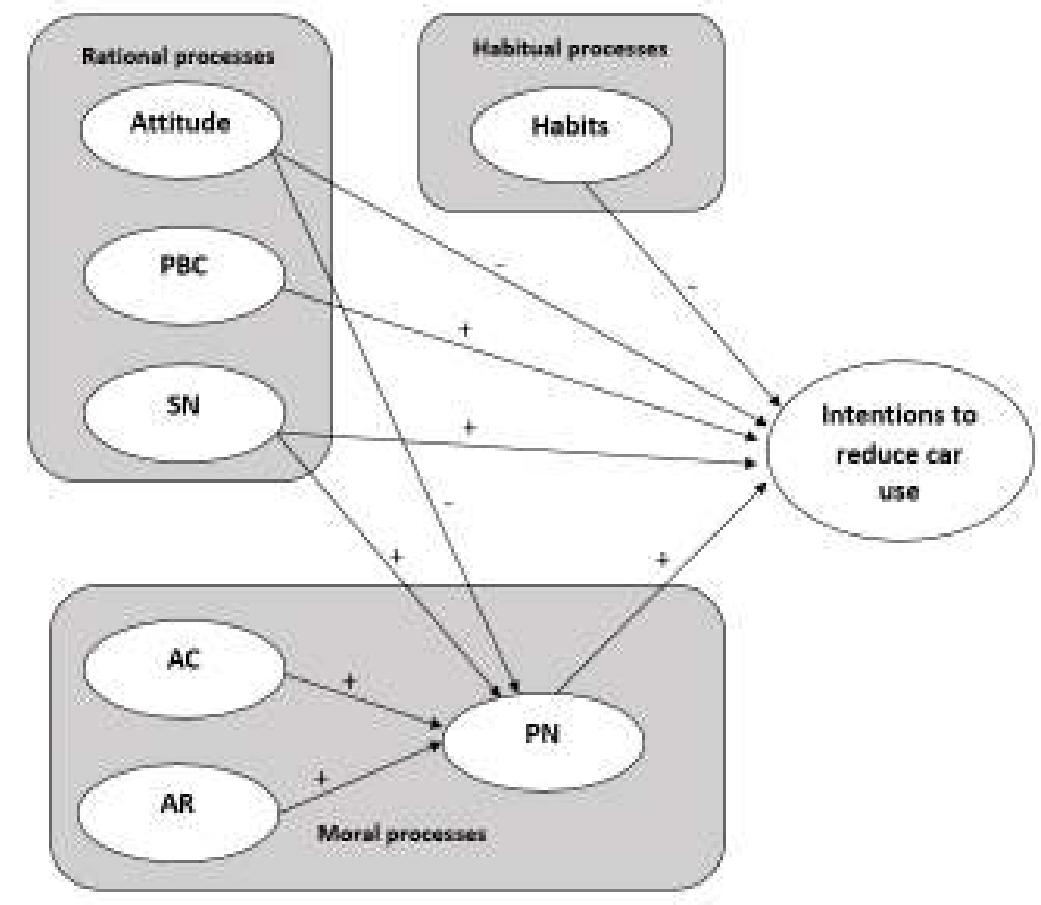

Figure 1. The specified integrative model

\section{Method}

Participants and procedure

Participants were recruited through the snowball method, online announcements and targeted advertising on Facebook, and were required to complete an online questionnaire. In order to reduce as much as possible the confounding effect of available infrastructure on our dependent variable, the survey was conducted on drivers from the same city. As incentive for participation, a prize consisting of a bicycle worth about 250 euros was offered randomly to one of the participants. In order to be eligible for the study, all participants were required to own a driver's license and to own a car or have access to one at all times. A total of 162 people completed our online questionnaire. Of these, 22 were removed: One participant reported an age under 18 , while 21 drivers did not own a car or had one at their disposal at any given moment. The final sample consisted therefore of 140 drivers, which were all residents in the city of Timişoara, the third largest city 
in Romania (about 320000 inhabitants). $92.2 \%$ of the participants in the final sample also owned a bicycle or had access to one at all times and were not therefore carcaptives. Participants were $56.4 \%$ female, they ranged in age from 18 to $61(M=32.592, S D=8.756)$, their highest educational level achieved was high school for $18.6 \%$, vocational training for $1.4 \%$, university for $36.4 \%$, master for $33.6 \%$ and doctorate for $10 \%$, while their mean net income ranged from 10 to 50000 RON a month $(M=$ $3592.518 \cong 760$ euro, $S D=4444.157)$. Seven participants did not report their monthly income. Regarding their car use, $1.4 \%$ of participants stated that they never use their car, $13.6 \%$ use it rarely, $24.3 \%$ use it sometimes, $20 \%$ use it often, $20.7 \%$ very often and $20 \%$ use it daily.

\section{Measures}

Participants' intention to reduce their car use was the dependent variable and was measured with two items on a 7-point scale: "My intention to reduce my car use in the near future is" ( 1 = weak, $7=$ strong) and "I intend to reduce my car use in the near future" $(1=$ unlikely, $7=$ likely). Cronbach's alpha was, $\alpha=.938$.

\section{Variables specific to $T P B$}

Attitudes towards car use were measured with five semantic differentials, each on a 7-point scale. Participants had to rate to what extent traveling by car is unattractive/attractive, bad/good, harmful/beneficial, unpleasant/pleasant and unworthy/valuable. Higher scores indicated more favorable attitudes towards car transportation. Cronbach's alpha was, $\alpha=.854$.

Subjective norms ( $S N)$ were assessed with four items measured on a 7 -point scale $(1=$ totally disagree; $7=$ totally agree) adapted from Bamberg et al. (2003): "Most people who are important to me would support me in using the car less", "Most people who are important to me think that I should reduce car transport", "Most people who are important to me use the car only when necessary" and "Most people who are important to me use sustainable means of transportation such as the bicycle, walking or public transportation, most of the time". Cronbach's alpha was, $\alpha=.689$.

Perceived behavioral control (PBC) was measured with two items adapted from Bamberg et al. (2003), both measured on a 7-point scale: "For me to reduce my car use in the future would be" ( 1 = difficult; 7 = easy $)$ and "My freedom to reduce my car use in the future is" $(1=$ low; $7=$ high). Cronbach's alpha was, $\alpha=.901$.

\section{Variables specific to NAM}

Awareness of consequences (AC) of car use was measured with a scale used by Ünal, Steg and Gorsira (2018). Respondents had to rate on a 7-point scale the extent to which they agree or disagree $(1=$ totally disagree, 7 = totally agree) with the following items: "The greenhouse effect resulting from road traffic is a serious problem", "Air pollution resulting from car traffic is a serious problem", "The $\mathrm{CO} 2$ emissions resulting from road traffic is a serious problem", "The emission of particulate matter by motor vehicles is a serious problem", "I am concerned about global warming resulting from road traffic", "I am concerned about the emissions of particulate matter resulting from road traffic", and "I am concerned about $\mathrm{CO} 2$ emissions resulting from road traffic". Cronbach's alpha of the scale was, $\alpha=.946$.

Ascription of responsibility (AR) was measured with a scale composed of three items adapted from Jakovcevic and Steg (2013). Participants had to rate on a 7-point scale their agreement or disagreement $(1=$ totally disagree, $7=$ totally agree) with the following items: "I am jointly responsible for the problems caused by car use", "Not just others, like the government, are responsible for heavy traffic, but me too" and "I feel joint responsibility for the contribution of car traffic to global warming”. Cronbach's alpha was $\alpha=.862$.

Personal norms $(P N)$ were assessed with an 8-item scale used by Jakovcevic and Steg (2013). Participants had to rate their agreement on a 7 -point scale $(1=$ totally disagree, 7 = totally agree) with the statements: "I feel personally obliged to travel in an environmentally sound way, such as by using a bicycle or public transport", "I would be a better person if I used more often other transport modes instead of the car", "People like me should do whatever they can to minimize their car use", "I feel obliged to take the environmental consequences of car use into account when making travel choices", "I don't feel guilty when I use the car even though there are other feasible transport alternatives available" (reverse coded), "If I buy a new car, I feel morally obliged to buy an energy-efficient car", "I feel morally obliged to use the car as little as possible, regardless of what other people do" and "I don't feel personally obliged to use the car as little as possible" (reverse coded). Cronbach's alpha was, $\alpha=$ .853 .

\section{Habits}

Habits were assessed with the self-report index of habit strength (SRHI, Verplanken \& Orbell, 2003). Respondents rated on a 5-point scale $(1=$ strongly disagree, $5=$ strongly agree) their agreement with the 12 items of the scale (e.g. "Using the car is something I do automatically", "Using the car is something that belongs to my everyday routine ", etc.). Cronbach's alpha was, $\alpha=.932$.

\section{Statistical analyses}

The analysis was conducted using a structural equation modeling (SEM) approach, with the help of IBM Amos version 22 software. An initial exploratory factor analysis (EFA) was conducted on all items to check the convergent and discriminant validity of the eight-factor structure proposed. Next, a measurement model for the latent factors was tested in a confirmatory factor analysis (CFA). After a good fit of the measurement model was obtained, the structural models were specified and hypotheses were tested.

\section{Preliminary analyses}

\section{Results}

With the exception of seven participants that failed to declare their income, there were no missing values on any of the measured variables. For these seven participants, income data was imputed using a regression approach. Unengaged responding was checked by inspecting the standard deviations across all responses, for each individual participant. No obvious cases of unengaged responding were revealed. A check for normality revealed fairly normal distributions for all indicators of latent factors in terms of skewness and kurtosis. However there were some deviations in kurtosis for some of the indicators of awareness of consequences ( $\mathrm{AC} 1, \mathrm{AC} 2, \mathrm{AC} 3$ and $\mathrm{AC} 4$ ), which had kurtosis values higher than 3 . Nevertheless, with the exception of the indicator $\mathrm{AC} 2$, all other kurtosis values were within a more relaxed criteria proposed by Hair, Black, Babin and Anderson (2010), who argued that 
data could be considered normal if skewness values are between -3 and 3 an kurtosis values are between -7 and 7 . We therefore decided to keep all other indicators of awareness of consequences and to remove only AC2 from our subsequent analyses.

In the next step, an exploratory factor analysis (EFA) was conducted, in order to inspect whether the expected eight-factor structure had good convergent and discriminant validity. Principal axis factoring with Promax rotation was used as the extraction method. Kaiser-MeyerOlkin measure of sampling adequacy was good $(K M O=$ $.841, p<.001$ ), indicating that the data is suitable for factor analysis. Due to low loadings on factors and as indicated by reliability analysis, indicators SN2, PN5, PN6, PN8, HAB4, HAB5, HAB9 and HAB12 were removed, in order to improve the factor structure. Seven factors with eigenvalues higher than 1 were extracted, explaining together about $68 \%$ of the variability. Convergent validity was good, as indicated by the loading amplitude on the pattern matrix, while discriminant validity was satisfactory, as there were no cross loadings higher than .35 nor factor correlations higher than .7. Indicators of intentions to reduce car use (INT1 and INT2) and those of perceived behavioral control ( $\mathrm{PBC} 1$ and $\mathrm{PBC} 2$ ) loaded on the same factor. However, this factor separated into the two expected factors when these four items were analyzed separately in another EFA. The correlation between the two factors was still reasonable $(r=.701)$, therefore we kept intention and $P B C$ as two separate factors in all subsequent analyses.

Confirmatory factor analysis

Due to model fit discrepancies, the indicators AC1, $\mathrm{AC} 4, \mathrm{PN} 2, \mathrm{PN} 3, \mathrm{HAB} 1, \mathrm{HAB} 3$ and HAB11 were removed. However, these items belonged to large latent reflective factors and were thus somewhat redundant. The eight-factor measurement model showed a good fit of the data, $\chi^{2}=456.507, \mathrm{df}=296, \chi^{2} / \mathrm{df}=1.542$, RMSEA $=.062$ $(.051, .074), \mathrm{CFI}=.940, \mathrm{SRMR}=.059$.

A check for common method bias (CMB) identified some bias in our model, as indicated by a significant chisquare difference between a zero-constrained and an unconstrained model with a common latent factor. However, the bias was very small, as only $6.2 \%$ of the total variance was explained by the common method used to collect the data.

A final validity check revealed good convergent validity for our factors (as indicated by AVE values close to or higher than .5), good discriminant validity (as indicated by square root values of AVE higher than the correlations between factors) and good reliability of the measures (as indicated by Cronbach's alpha values close to or higher than .70). Table 1 contains a full description of the validity measures.

\section{Structural Equation Modeling}

In order to check for multivariate assumptions, we first created imputed values for all our factors. We examined variable inflation factors (VIF) for all predictors on our DV and observed no values greater than 2.169. This indicated that there are no serious multicolinearity problems. We checked for multivariate influential points by studying Cook's distances and observed no values greater than .154, indicating that there are no multivariate influential points.

\section{Testing TPB model}

The fit indices for TPB model showed a good fit, $\chi^{2}=$ 93.106, $\mathrm{df}=48, \chi^{2} / \mathrm{df}=1.940, \mathrm{RMSEA}=.082(.057, .107)$, $\mathrm{CFI}=.950$, SRMR $=.063$. As predicted by the model, intentions to reduce car use were positively predicted by PBC $(\beta=.632, t=7.262, p<.001)$ and negatively predicted by attitudes towards car use $(\beta=-.234, t=$ $3.013, p=.003)$. However, $S N$ did not significantly predict intentions to reduce car transport $(\beta=-.001, t=-.011, p=$ $.992)$. The total variability in intentions predicted by the three predictors of the model was $R^{2}=.594$ (see Table 2).

\section{Testing NAM model}

The fit indices for the NAM model showed a good fit, $\chi^{2}=106.469, \mathrm{df}=50, \chi^{2} / \mathrm{df}=2.129$, RMSEA $=.090(.066$, $.114)$, CFI $=.960$, SRMR $=.058$. As specified by the NAM, intentions to reduce car use were positively predicted by $P N(\beta=.515, t=6.291, p<.001)$ which, in turn, were predicted by $A C(\beta=.546, t=6.239, p<.001)$ and $A R(\beta=.264, t=3.261, p=.001)$. The model explained about $26 \%$ of the variability in intentions $\left(R^{2}=\right.$ $.265)$.

Table 1. Validity measures and factor correlation matrix

\begin{tabular}{|c|c|c|c|c|c|c|c|c|c|c|}
\hline & Alpha & AVE & Habits & AC & Attitudes & Intention & PN & $\mathbf{A R}$ & SN & PBC \\
\hline Habits & 0.909 & 0.666 & 0.816 & & & & & & & \\
\hline $\mathrm{AC}$ & 0.940 & 0.799 & -0.080 & 0.894 & & & & & & \\
\hline Attitudes & 0.857 & 0.549 & $0.357^{* * *}$ & $-0.209^{*}$ & 0.741 & & & & & \\
\hline Intention & 0.938 & 0.883 & $-0.342^{* * *}$ & $0.261^{* *}$ & $-0.535^{* * *}$ & 0.940 & & & & \\
\hline PN & 0.896 & 0.742 & $-0.370^{* * *}$ & $0.650^{* * *}$ & $-0.513^{* * *}$ & $0.529^{* * *}$ & 0.862 & & & \\
\hline $\mathbf{A R}$ & 0.867 & 0.685 & 0.034 & $0.366^{* * *}$ & -0.182 & 0.161 & $0.475^{* * *}$ & 0.828 & & \\
\hline SN & 0.698 & 0.443 & $-0.287^{*}$ & 0.073 & -0.142 & $0.246^{*}$ & $0.318^{* *}$ & 0.065 & 0.666 & \\
\hline PBC & 0.903 & 0.824 & $-0.586^{* * *}$ & $0.204^{*}$ & $-0.478^{* * *}$ & $0.742^{* * *}$ & $0.387^{* * * *}$ & 0.129 & $0.345^{* *}$ & 0.908 \\
\hline
\end{tabular}

Notes: ${ }^{*} p<.05,{ }^{* *} p<.01,{ }^{* * *} p<.001 \mathrm{SN}=$ subjective norms; $\mathrm{PBC}=$ perceived behavioral control; $\mathrm{PN}=$ personal norms; $\mathrm{AC}=$ awareness of consequences; AR = ascription of responsibility; Alpha = Cronbach's alpha; AVE = average variance extracted;

The square root values of AVE are positioned on the diagonal, while correlation coefficients between factors are placed in non-diagonal positions. 
Table 2. Estimated parameters and fit indices of the tested models

\begin{tabular}{|c|c|c|c|c|c|c|c|c|c|}
\hline Model & Path & $\beta$ & $p$ & $\chi^{2}$ & $d f$ & RMSEA & CFI & SRMR & $R^{2}$ \\
\hline \multirow[t]{4}{*}{ TPB } & & & & 93.106 & 48 & .082 & .950 & .063 & .594 \\
\hline & ATT $\rightarrow$ Intention & -.234 & .003 & & & & & & \\
\hline & $\mathrm{SN} \rightarrow$ Intention & -.001 & .992 & & & & & & \\
\hline & $\mathrm{PBC} \rightarrow$ Intention & .632 & $<.001$ & & & & & & \\
\hline \multirow[t]{4}{*}{ NAM } & & & & 106.469 & 50 & .090 & .960 & .058 & .265 \\
\hline & $\mathrm{PN} \rightarrow$ Intention & .515 & $<.001$ & & & & & & \\
\hline & $\mathrm{AC} \rightarrow \mathrm{PN}$ & .546 & $<.001$ & & & & & & \\
\hline & $\mathrm{AR} \rightarrow \mathrm{PN}$ & .264 & .001 & & & & & & \\
\hline \multirow[t]{9}{*}{ TPB \& NAM } & & & & 321.501 & 197 & .067 & .942 & .094 & .613 \\
\hline & ATT $\rightarrow$ Intention & -.144 & .075 & & & & & & \\
\hline & $\mathrm{SN} \rightarrow$ Intention & -.052 & .512 & & & & & & \\
\hline & $\mathrm{PBC} \rightarrow$ Intention & .614 & $<.001$ & & & & & & \\
\hline & $\mathrm{PN} \rightarrow$ Intention & .241 & .001 & & & & & & \\
\hline & $\mathrm{AC} \rightarrow \mathrm{PN}$ & .510 & $<.001$ & & & & & & \\
\hline & $\mathrm{AR} \rightarrow \mathrm{PN}$ & .234 & .002 & & & & & & \\
\hline & $\mathrm{SN} \rightarrow \mathrm{PN}$ & .235 & .005 & & & & & & \\
\hline & $\mathrm{ATT} \rightarrow \mathrm{PN}$ & -.366 & $<.001$ & & & & & & \\
\hline \multirow[t]{15}{*}{$\begin{array}{l}\text { TPB \& NAM \& } \\
\text { habits }\end{array}$} & Direct effects & & & 478.721 & 308 & .063 & .936 & .087 & .639 \\
\hline & ATT $\rightarrow$ Intention & -.147 & .075 & & & & & & \\
\hline & $\mathrm{SN} \rightarrow$ Intention & -.032 & .691 & & & & & & \\
\hline & $\mathrm{PBC} \rightarrow$ Intention & .727 & $<.001$ & & & & & & \\
\hline & $\mathrm{PN} \rightarrow$ Intention & .248 & $<.001$ & & & & & & \\
\hline & Habits $\rightarrow$ Intention & .214 & .012 & & & & & & \\
\hline & $\mathrm{AC} \rightarrow \mathrm{PN}$ & .508 & $<.001$ & & & & & & \\
\hline & $\mathrm{AR} \rightarrow \mathrm{PN}$ & .236 & .001 & & & & & & \\
\hline & $\mathrm{SN} \rightarrow \mathrm{PN}$ & .247 & .003 & & & & & & \\
\hline & $\mathrm{ATT} \rightarrow \mathrm{PN}$ & -.369 & $<.001$ & & & & & & \\
\hline & Indirect effects & & & & & & & & \\
\hline & $\mathrm{AC} \rightarrow \mathrm{PN} \rightarrow$ Intention & .126 & .002 & & & & & & \\
\hline & $\mathrm{AR} \rightarrow \mathrm{PN} \rightarrow$ Intention & 059 & .008 & & & & & & \\
\hline & $\mathrm{SN} \rightarrow \mathrm{PN} \rightarrow$ Intention & .061 & .003 & & & & & & \\
\hline & $\mathrm{ATT} \rightarrow \mathrm{PN} \rightarrow$ Intention & -.092 & .002 & & & & & & \\
\hline
\end{tabular}




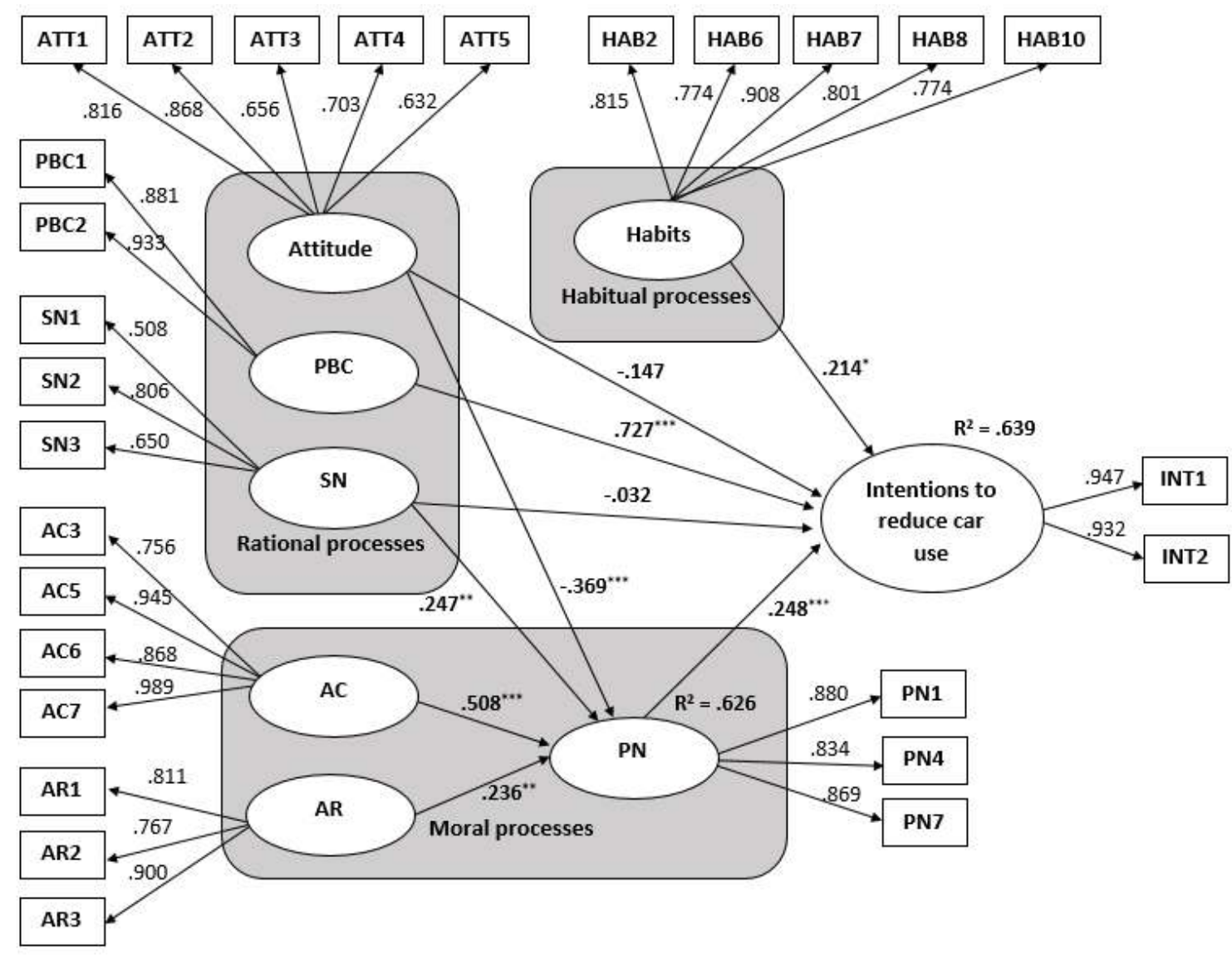

Figure 2. Structural model with standardized path coefficients and explained variance in intentions and personal norms.

\section{Testing TPB \& NAM}

The fit indices for the integrated model between TPB and NAM also showed a good fit, $\chi^{2}=321.501, \mathrm{df}=197$, $\chi^{2} / \mathrm{df}=1.632, \mathrm{RMSEA}=.067(.054, .081), \mathrm{CFI}=.942$, $\mathrm{SRMR}=.094$. In this model, intentions to reduce car use were predicted only by $P B C(\beta=.614, t=7.285, p<.001)$ and $P N(\beta=.241, t=3.269, p=.001)$, while attitudes $(\beta=$ $-.144, t=-1.783, p=.075)$ and $S N(\beta=-.052, t=-.656, p=$ $.512)$ did not significantly predict intentions. $P N$ were predicted by $A R(\beta=.234, t=3.153, p=.002), A C(\beta=$ $.510, t=6.291, p<.001), S N(\beta=.235, t=2.806, p=.005)$ and attitudes $(\beta=-.366, t=-5.016, p<.001)$. Integrating TPB with NAM explained an additional $2 \%$ of the variability in intentions to reduce car transport $\left(R^{2}=.613\right)$, over the one already explained by TPB.

\section{Testing TPB \& NAM \& Habits}

The structural model with standardized estimates is shown in Figure 2. In the specified model, only the following constructs were covaried: $A C$ with $A R$ and attitudes, $S N, P B C$ and habits with each other. The model fit indices showed a good fit, $\chi^{2}=478.721, \mathrm{df}=308, \chi^{2} / \mathrm{df}$ $=1.554, \mathrm{RMSEA}=.063(.052, .074), \mathrm{CFI}=.936, \mathrm{SRMR}=$ .087. Adding the construct of habits to TPB and NAM increased the percentage of explained variability in intentions with about $2 \%\left(R^{2}=.639\right)$.

\section{Direct effects}

As expected, intentions to reduce car use were significantly predicted by $P B C(\beta=.727 t=7.288, p<$ $.001)$ and $P N(\beta=.248, t=3.344, p<.001)$. On the other hand, attitudes $(\beta=-.147, t=-1.777, p=.075)$ and $S N(\beta=$ $-.032, t=-.398, p=.691)$ did not directly predict intentions to reduce car transport, as we hypothesized. Concerning personal norms, as expected, $P N$ were significantly predicted by attitudes $(\beta=-.369, t=-5.073, p<.001), S N$ $(\beta=.247, t=2.928, p=.003), A C(\beta=.508, t=6.297, p<$ $.001)$ and $A R(\beta=.236, t=3.193, p=.001)$. A surprising finding was that habits positively predicted intentions to reduce car use $(\beta=.214, t=2.525, p=.012)$, indicating that people with stronger habits also had stronger intentions to reduce car transport. This result is contrary to what we expected.

\section{Mediated effects}

Indirect effects on intention to reduce car transportation were tested in AMOS software. Results based on 5000 bootstrapped samples showed that the indirect effect of $A C$ on intentions to reduce car use was significant, $\beta=.238, p$ $=.002$, and was mediated by $P N$. Similarly, $A R(\beta=.090, p$ $=.008), S N(\beta=.121, p=.003)$ and attitudes $(\beta=-.099, p$ $=.002)$ had significant indirect effects on intentions to reduce car use, which were all mediated by $P N$. 


\section{Discussion}

The main goal of the present study was to propose and test a model that integrates rational, moral and habitual processes in explaining intentions to reduce car transportation. Specifically, we proposed a model that integrates the TPB, the NAM and the construct of habits and tested its predictive power against already established theories such as TPB, NAM and a combination of both. Model fit indices revealed a good fit and all variables proposed in the model showed an effect (direct or indirect) on intentions to reduce car use. Tested against the compared models, the integrated model we propose explains the largest degree of variability in intentions to reduce car use, which suggests that such a comprehensive model can be regarded as more appropriate for explaining car use intentions.

Our results show that, whereas for the NAM all specified relations between model constructs were confirmed empirically, the expected relations in the TPB were only partly confirmed. Subjective norms (SN) did not significantly predict intentions to reduce car use, as expected in the TPB model, indicating that driver's intentions to change their travel patterns were not influenced directly by social pressures. A similar result was found by Abrahamse et al. (2009), who showed that SN failed to predict intentions to reduce car use for commuting in a sample of Canadian employees. Comparing the two models in terms of explained variance, the TPB was more adequate than the NAM at predicting driver's intentions to reduce car use (59\% vs. 27\%). Steg and Vlek (2009) argue that, in situations characterized by high behavioral costs (such as reducing car transportation), the TPB performs better than the NAM because it includes a wider array of factors (see also Bamberg \& Schmidt, 2003; Liu et al., 2017), while the NAM may be more suited in predicting low cost pro-environmental behaviors, such as acceptance of TDM policies (e.g. Eriksson, Garvill, \& Nordlund, 2006). The integrated model we proposed performed significantly better than TPB, NAM or the combination of the two and explained about $64 \%$ of the total variability in intentions to reduce car use. Our results suggest that, besides rational decisional processes, moral and habitual factors also play an important role in influencing the degree to which people are willing to act proenvironmentally and change their transportation patterns. Path coefficients show that the most important determinant of driver's intentions to reduce car use is perceived behavioral control $(\beta=.727)$, indicating that the more people perceive is within their reach to change their transportation style, the stronger their intention to reduce car use is. An examination of the other effects shows that, besides PBC, the most important factors impacting driver's intention to change their transport patterns are personal norms $(\beta=.248)$ and habits $(\beta=.214)$. As expected, stronger feelings of moral obligation to reduce car use were associated with stronger intentions to actually do so. Surprisingly, habits were a direct and positive predictor of intentions. In other words, stronger habits corresponded to stronger intentions of change, a result that was contrary to what we expected. However, a closer inspection of the relation between habits and ascription of responsibility (AR) revealed that habits were a significant positive predictor of the latter when attitudes towards car use, $\mathrm{PBC}$, $\mathrm{SN}, \mathrm{PN}$ and $\mathrm{AC}$ were controlled for $(\beta=.280, t(134)=$ $2844, p=.005)$. This shows that drivers with stronger habits felt significantly more responsible for the negative environmental consequences resulting from their car use than drivers with weak habits. The increased felt responsibility together with the negative affects that may stem from it, can offer a plausible explanation for why drivers with strong habits have stronger intentions for change.

In the proposed model, attitudes and subjective norms related to car transportation did not directly impact driver's intention to reduce their car use. As hypothesized however, both variables had an indirect effect, which was mediated by personal norms. Drivers with more favorable attitudes towards car transport had a weaker intention to reduce their car use $(\beta=-.092)$, while drivers who, in their social environment, had stronger norms against car use, had stronger intentions to change their travel patterns $(\beta=$ $.061)$. Personal norms mediated the path from subjective norms to intentions, which is a result that supports the internalization hypothesis of social norms into personal ones (see Klöckner \& Matthies, 2009). As such, our results support the normative and attitudinal influences on intentions and justify their inclusion in the integrated model, even though the direct paths failed to be significant. As predicted by the NAM, results also showed that the more drivers were aware of the negative environmental consequences of driving and the more they believed they can alleviate such consequences, the more they intended to change their behavior. These conclusions were substantiated by the significant indirect effects of awareness of consequences $(\beta=.126)$ and ascription of responsibility $(\beta=.059)$ on intentions to reduce car transport, which were mediated by personal norms.

The practical implications of the current findings are important, especially in the current context of escalating air pollution in many cities and rising global levels of greenhouse gases. The proposed model addresses driver's intention to reduce car use from a psychological perspective, by integrating rational, moral and habitual factors in a comprehensive model.

From an interventionist viewpoint, it proposes a practical framework that policymakers could use to inform the development of TDM solutions aimed at changing drivers' transportation patters. Having a priori knowledge about the most important determinants of behavioral intentions, future interventions can be conceived to maximize their efficacy, while minimizing their associated costs and risks. Based on the results of the present study, promoting drivers' perceived behavioral control over car use reduction can prove to be especially important. Also, future policies should focus on encouraging drivers' feelings of moral obligation (i.e. personal norms) by targeting its important antecedents such as attitudes, AC or AR. Interventions should make drivers aware of the negative consequences that driving has over the environment, while at the same time encourage their feelings of responsibility by emphasizing how changes in their behavior could mitigate such consequences. Educational interventions should focus on encouraging people to form positive attitudes towards sustainable means of transportation and on addressing overly positive attitudes towards car transportation. An advantage of such TDM policies is that, unlike structural or "hard" policies (see Möser \& Bamberg, 2008), they are better accepted by the public. However, policymakers should be realistic about the expected outcomes of such policies, as car use is a high cost behavior that is particularly difficult to change (Steg \& Vlek, 2009). 
Limitations and future studies

The present study focused on integrating different psychological predictors of intention to reduce car use in a single model. Even though the model explained most of the variability, intentions to reduce car transport are influenced by more antecedents than just psychological ones. For instance, situational conditions such as availability of alternative transport infrastructure, road conditions, availability of parking spaces or traffic conditions, are other possible antecedents that future studies could explore. Consequently, the proposed framework could be developed to include also such factors.

A second limitation lies in the generalizability of our results. Since the survey was conducted online, it is likely that the drivers in our sample are not fully representative for the population of drivers in Romania. This is also evidenced by the high proportion of drivers in our sample that completed tertiary education. We also have to acknowledge that the support found for the proposed model in the domain of travel mode choice does not necessarily mean that the model is suited to explain other types of pro-environmental intentions or behaviors. Future studies will therefore need to validate such findings by replicating them on more representative and diverse samples and by considering other domains of ecological behavior.

A third limitation lies in the slight common method bias that was introduced during data collection. Even though this bias is very small (only $6.2 \%$ of the total variance), it slightly inflated the associations between the factors in the model and, consequently, inflated the path coefficients. It is therefore likely that if no bias would have been present, these coefficients would be slightly lower than the ones we reported.

Besides measuring behavioral intentions, it is also important to measure actual car use behavior as, from a practical standpoint, it is the outcome that practitioners and policymakers are most interested to modify. Even though empirical evidence suggests that intentions are the strongest predictor of actual behavior (see Lanzini \& Khan, 2017), evidence consistently shows an intention - behavior gap. Therefore, in order to provide an enhanced understating of mobility behaviors, future studies will need to explore to what extent the integrated model we propose is valid in explaining actual car use behavior.

\section{Conflicts of interest}

The authors declare that there is no conflict of interest.

\section{Acknowledgments}

Publishing current paper was financed through Entrepreneurial Education and Professional Counseling for Social and Human Sciences for PhD and Postdoctoral Researchers to ensure knowledge transfer Project, financed through Human Capital Programme (ATRiUM, POCU380/6/13/123343, Lead Beneficiary: West University of Timişoara).

\section{References}

Abrahamse, W., Steg, L., Gifford, R., \& Vlek, C. (2009). Factors influencing car use for commuting and the intention to reduce it: A question of self-interest or morality?. Transportation Research Part F: Traffic Psychology and Behaviour, 12(4), 317-324. https://doi.org/10.1016/j.trf.2009.04.004
Ajzen, I. (1991). The theory of planned behavior. Organizational behavior and human decision processes, 50(2), 179-211.

Bamberg, S., \& Schmidt, P. (1998). Changing travel-mode choice as rational choice: Results from a longitudinal intervention study. Rationality and Society, 10(2), 223252. https://doi.org/10.1177/104346398010002005

Bamberg, S., \& Schmidt, P. (2003). Incentives, morality, or habit? Predicting students' car use for university routes with the models of Ajzen, Schwartz, and Triandis. Environment and behavior, 35(2), 264-285. https://doi.org/10.1177/0013916502250134

Bamberg, S., (2006). Is a Residential Relocation a Good Opportunity to Change People's Travel Behavior? Results From a Theory-Driven Intervention Study. Environ. Behav. 38, 820-840 https://doi.org/10.1177/0013916505285091

Bamberg, S., Ajzen, I., \& Schmidt, P. (2003). Choice of travel mode in the theory of planned behavior: The roles of past behavior, habit, and reasoned action. Basic and applied social psychology, 25(3), 175-187. https://doi.org/10.1207/S15324834BASP2503 01

Bamberg, S., Rees, J. (2017). The impact of voluntary travel behavior change measures - A meta-analytical comparison of quasi-experimental and experimental evidence. Transp. Res. Part A Policy Pract. 100, 16-26. https://doi.org/10.1016/j.tra.2017.04.004

Baslington, H. (2008). Travel socialization: A social theory of travel mode behavior. International Journal of Sustainable Transportation, 2(2),

91-114. https://doi.org/10.1080/15568310601187193

Black, J. S., Stern, P. C., \& Elworth, J. T. (1985). Personal and contextual influences on househould energy adaptations. Journal of applied psychology,70(1), 3. https://doi.org/10.1037/0021-9010.70.1.3

Boldero, J. (1995). The Prediction of Household Recycling of Newspapers: The Role of Attitudes, Intentions, and Situational Factors 1. Journal of Applied Social Psychology, 25(5), 440-462. https://doi.org/10.1111/j.1559-1816.1995.tb01598.x

Bratt, C. (1999). The impact of norms and assumed consequences on recycling behavior. Environment and behavior, 31(5), https://doi.org/10.1177/00139169921972272

Chng, S., Abraham, C., White, M. P., Hoffmann, C., \& Skippon, S. (2018). Psychological theories of car use: An integrative review and conceptual framework. Journal of Environmental Psychology, 55, 23-33. https://doi.org/10.1016/j.jenvp.2017.10.009

Cordano, M., Welcomer, S., Scherer, R. F., Pradenas, L., \& Parada, V. (2011). A cross-cultural assessment of three theories of pro-environmental behavior: A comparison between business students of Chile and the United States. Environment and Behavior, 43(5), 634-657. https://doi.org/10.1177/0013916510378528

Eriksson, L., Garvill, J., \& Nordlund, A. M. (2006). Acceptability of travel demand management measures: The importance of problem awareness, personal norm, freedom, and fairness. Journal of environmental psychology, 26(1), https://doi.org/10.1016/j.jenvp.2006.05.003

Eriksson, L., Garvill, J., \& Nordlund, A. M. (2008) Interrupting habitual car use: The importance of car habit strength and moral motivation for personal car use reduction. Transportation Research Part F: Traffic Psychology and Behaviour, 11(1), 10-23. https://doi.org/10.1016/j.trf.2007.05.004

European Environment Agency (2018, June 11). Electric vehicles as a proportion of the total fleet. Retrieved from https://www.eea.europa.eu/data-and- 
maps/indicators/proportion-of-vehicle-fleet-meeting4/assessment-4. Last accessed, December 2019.

Hair, J. F., Black, W. C., Babin, B. J., \& Anderson, R. E. (2010). Multivariate data analysis: Global edition.

Harland, P., Staats, H., \& Wilke, H. A. (1999). Explaining proenvironmental intention and behavior by personal norms and the Theory of Planned Behavior 1. Journal of applied social psychology,29(12), 2505-2528. https://doi.org/10.1111/j.1559-1816.1999.tb00123.x

Haustein, S., \& Hunecke, M. (2007). Reduced use of environmentally friendly modes of transportation caused by perceived mobility necessities: An extension of the theory of planned behavior 1. Journal of Applied Social Psychology, 37(8), 1856-1883. https://doi.org/10.1111/j.1559-1816.2007.00241.x

Heath, Y., \& Gifford, R. (2002). Extending the theory of planned behavior: Predicting the use of public transportation 1. Journal of Applied Social Psychology, 32(10), 2154-2189. https://doi.org/10.1111/j.1559-1816.2002.tb02068.x

Hopper, J. R., \& Nielsen, J. M. (1991). Recycling as altruistic behavior: Normative and behavioral strategies to expand participation in a community recycling program. Environment and behavior, 23(2), 195-220. https://doi.org/10.1177/0013916591232004

Hunecke, M., Blöbaum, A., Matthies, E., \& Höger, R. (2001). Responsibility and environment: Ecological norm orientation and external factors in the domain of travel mode choice behavior. Environment and behavior, 33(6), 830-852. https://doi.org/10.1177/00139160121973269

Jakovcevic, A., \& Steg, L. (2013). Sustainable transportation in Argentina: Values, beliefs, norms and car use reduction. Transportation Research Part F: Traffic Psychology and Behaviour, 20, 70-79. https://doi.org/10.1016/j.trf.2013.05.005

Klöckner, C. A., \& Blöbaum, A. (2010). A comprehensive action determination model: Toward a broader understanding of ecological behaviour using the example of travel mode choice. Journal of Environmental Psychology, 30(4),

574-586. https://doi.org/10.1016/j.jenvp.2010.03.001

Klöckner, C. A., \& Matthies, E. (2009). Structural Modeling of Car Use on the Way to the University in Different Settings: Interplay of Norms, Habits, Situational Restraints, and Perceived Behavioral Control 1. Journal of Applied Social Psychology,39(8), 1807-1834. https://doi.org/10.1111/j.1559-1816.2009.00505.x

Lam, S. P. (1999). Predicting intentions to conserve water from the theory of planned behavior, perceived moral obligation, and perceived water right 1. Journal of Applied Social Psychology,29(5), 1058-1071. https://doi.org/10.1111/j.1559-1816.1999.tb00140.x

Lanzini, P., \& Khan, S. A. (2017). Shedding light on the psychological and behavioral determinants of travel mode choice: A meta-analysis. Transportation research part $F$ : traffic psychology and behaviour, 48, 13-27. https://doi.org/10.1016/i.trf.2017.04.020

Liu, Y., Sheng, H., Mundorf, N., Redding, C., \& Ye, Y. (2017). Integrating norm activation model and theory of planned behavior to understand sustainable transport behavior: Evidence from China. International journal of environmental research and public health, 14(12), 1593. https://doi.org/10.3390/ijerph14121593

Lois, D., Moriano, J. A., \& Rondinella, G. (2015). Cycle commuting intention: A model based on theory of planned behaviour and social identity. Transportation research part F: traffic psychology and behaviour, 32, 101-113. https://doi.org/10.1016/j.trf.2015.05.003

Möser, G., Bamberg, S., 2008. The effectiveness of soft transport policy measures: A critical assessment and metaanalysis of empirical evidence. J. Environ. Psychol. 28, 10-26. https://doi.org/10.1016/j.jenvp.2007.09.001

Noblet, C. L., Thøgersen, J., \& Teisl, M. F. (2014). Who attempts to drive less in New England?. Transportation research part F: traffic psychology and behaviour, 23, 6980. https://doi.org/10.1016/j.trf.2013.12.016

Nordlund, A. M., \& Garvill, J. (2002). Value structures behind proenvironmental behavior. Environment and behavior, 34(6), 740-756. https://doi.org/10.1177/001391602237244

Nordlund, A. M., \& Garvill, J. (2003). Effects of values, problem awareness, and personal norm on willingness to reduce personal car use. Journal of environmental psychology, 23(4), 339-347. https://doi.org/10.1016/S0272-4944(03)00037-9

Schwartz, S. H. (1977). Normative influences on altruism. In L. Berkowitz (Ed.), Advances in experimental social psychology (Vol. 10, pp. 221-279). San Diego: Academic Press.

Steg, L., \& Vlek, C. (2009). Encouraging pro-environmental behaviour: An integrative review and research agenda. Journal of environmental psychology, 29(3), 309317. https://doi.org/10.1016/j.jenvp.2008.10.004

Ünal, A. B., Steg, L., \& Gorsira, M. (2018). Values versus environmental knowledge as triggers of a process of activation of personal norms for eco-driving. Environment and behavior, 50(10), 1092-1118. https://doi.org/10.1177/0013916517728991

Verplanken, B., \& Orbell, S. (2003). Reflections on past behavior: a self - report index of habit strength 1. Journal of applied social psychology,33(6), 1313-1330. https://doi.org/10.1111/j.1559-1816.2003.tb01951.x

Verplanken, B., Aarts, H., van Knippenberg, A., \& van Knippenberg, C. (1994). Attitude versus general habit: Antecedents of travel mode choice. Journal of Applied Social Psychology, 24(4), 285300. https://doi.org/10.1111/j.1559-1816.1994.tb00583.x

Verplanken, B., Aarts, H., van Knippenberg, A., 1997. Habit, information acquisition, and the process of making travel mode choices. Eur. J. Soc. Psychol. 27, 539-560. https://doi.org/10.1016/S0001-6918(97)00008-5

Verplanken, B., Aarts, H., van Knippenberg, A., Moonen, A., 1998. Habit versus planned behaviour: A field experiment. Br. J. Soc. Psychol. 37, 111-128. https://doi.org/10.1111/j.2044-8309.1998.tb01160.x 